\title{
Some meristic characteristics of hybrids between Acipenser naccarii and Acipenser baerii.
}

\author{
By G. Arlati ${ }^{1}$, J. A. Hernando ${ }^{2}$, L. A. Poliakova-Belysceva ${ }^{3}$ and M. C. Soriguer ${ }^{2}$. \\ 1.- Regione Lombardia, CRIAP-Ufficio Pesca, pzza IV novembre ,5 - 20124 MI (Italy). 2.- Departamento de Biologia Animal, \\ Biologia Vegetal y Ecologia. Facultad de Ciencias del Mar. 11510 Puerto Real. Cádiz (Spain). 3.- via Manzoni, 21 - 20095 Cusano \\ Milanino (Italy).
}

\section{Summary}

The aim of this study was to describe meristic characters of hybrid Acipenser naccarii $x A$. baeri, to be used as the basis for characterizing hybrid specimens in a complementary manner to as described for $A$. naccarii by Hernando et al. (1999). Thirty $2+$ and $3+$ year class individuals from the Region of Lombardy (Italy) were analysed for eight morphological variables (Soljan 1975; Holcick et al. 1989), and weight. Three indices, viz the relative position of barbels (CA), the ratio of snout width to length (FB) (Garrido-Ramos et al. 1997), and the Soljan index (Hernando et al. 1999), were used to characterize hybrids.

A descriptive analyses of variables, simple and multiple regression analysis, and principal components relationships, were calculated. The relationships between $\mathrm{Tl}$ and the indices was described using a stepwise multiple regression analysis: $\mathrm{Tl}=33.32$ $-0.26 \mathrm{CA}+10.49 \mathrm{FB}+74.45 \mathrm{SOLJ}(\mathrm{F}=1.96 ; \mathrm{Df}=3)$.

\section{Introduction}

The first generation of hybrids between Acipenser naccarii and Acipenser baeri was obtained in 1993 at the Azienda Agricola VIP (Orzinuovi, Brescia, Italy), and named "AL". These hybrids are now being used at several acquaculture facilities, and adapt well to intensive culture conditions. Because nothing is known about their meristics and morphometrics, a preliminary study on different age groups and both sexes was performed using 14 variables. The data bank developed will be of use to both scientists and practitioners for comparative studies of growth and sexual development.

\section{Materials and methods}

Thirty 2+ and 3+ year class individuals from the Azienda Agricola VIP (Orzinuovi, Brescia, Lombardy, Italy) were analysed. Eight variables were measured (Fig. 1): total length $(\mathrm{Tl}$, in $\mathrm{cm}$ ); standard length ( $\mathrm{Sl}$, in $\mathrm{cm}$ ); weight ( $\mathrm{W}$, in $\mathrm{g}$ ); distance from snout to the base of the barbels (s-b, in mm); width of the snout at the barbels (lab, in $\mathrm{mm}$ ); distance from the base of the barbels to the cartilaginous arch of mouth (b-mc, in $\mathrm{mm}$ ); distance from the tip of snout to the cartilaginous arch of mouth (s-mc, in mm); length of the head (hl, in $\mathrm{mm}$ ); anal scute series (AS); dorsal scute series (DS); left and right lateral scute series (LLS and RLS, respectively); left and right ventral scute series (LVS and RVS, respectively), and internal width of mouth (IWM, in mm).

In accordance with the nomenclature used by Soljan (1975) and Holcik et al. (1989), indices were defined in order to determine the relative position of the barbels $(C A=b-m c-s-b)$, the ratio of the length to the width of the snout ( $\mathrm{FB}=\mathrm{s}-\mathrm{mc}: \mathrm{lab}$ ) (Garrido-Ramos et al. 1997) and the ratio of mouth width to length of the snout, referred to as the Soljan index (SOLJ =s-mc : IWM) (Hernando et al. 1999).
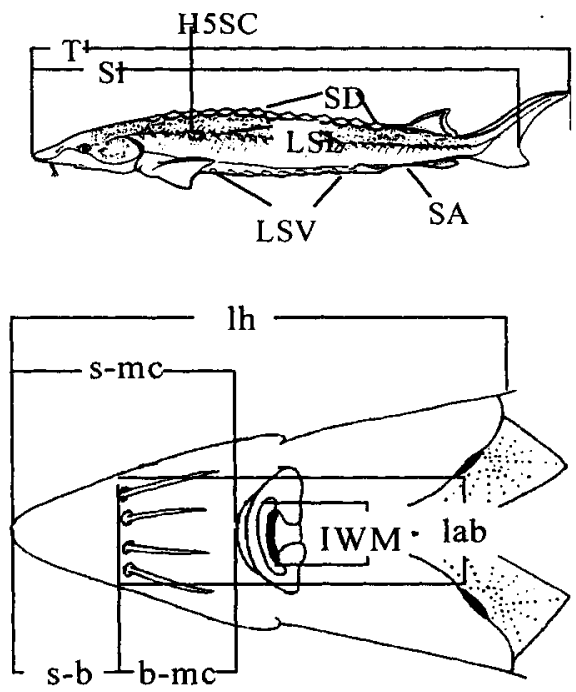

Fig 1.- Body and head morphometric characters on a schematic representation of an Acipenser naccarii, modified after Holcik et al (1989), used in this study. $\mathrm{Tl}$ (Total length in $\mathrm{cm}$ ), $\mathrm{Sl}$ (standard length in $\mathrm{cm}$ ), W ( weight in grs.), s-b (distance from snout to the base of the barbels in $\mathrm{mm}$ ), lab (width of the snout at the height of the barbels in $\mathrm{mm}$ ), b-mc (distance from the base of the barbels to the cartilaginous arch of mouth in $\mathrm{mm}$ ) s-mc (distance from the tip of snout to the cartilaginous arch of mouth in $\mathrm{mm}$ ), $\mathrm{hl}$ (length of the head in mm), scute series: anal (AS), dorsal (DS), lateral (left LLS and right RLS), ventral (left LVS and right RVS) and IWM (internal width of mouth in $\mathbf{m m}$ )

Statistical analyses were carried out using STATGRAPHICS ${ }^{\text {TM }}$ performing Multiple Comparisons, Simple Regression and Stewise Multiple Regression Analysis, and BMDP'M (Principal Components Analyses).

\section{Results and Discussion}

A descriptive analysis of the variables was conducted by calculating averages, standard deviations and ranges. Once differences among variables had been demonstrated by multiple comparison to be due only to growth (Df: $31 ; \mathrm{F}=1382.05 ; \mathrm{p}=$ 0 ), a Principal Components Analysis (PCA) was performed to determine the trend of the variations in the morphometric variables. Of the total accumulated variance, $71.48 \%$ was absorbed by analysis of its three components, distinguishing two wide groups (Fig 2A) (Table 1). The first one (LENGTHS) consists of all the morphometric variables related to the length of the individuals: $\mathrm{Tl}, \mathrm{Sl}, \mathrm{AGE}$, lab, IWM, b- mc, s-mc, and s-b. 
Thereby, the second one is composed of all the variables not related to the length. That is, the three indices and all the scutes series (INDICES \& SCUTES). However, the second group is not homogeneous, being composed of two subgroups. The first is a subgroup made up of the scutes series and the second one of the $\mathrm{CA}$ and the SOLJ index, being separated by FB. This analysis shows the relationship between $\mathrm{Tl}$ and the age of the exemplars, although independence of the index from the $\mathrm{Tl}$ is also demonstrated.

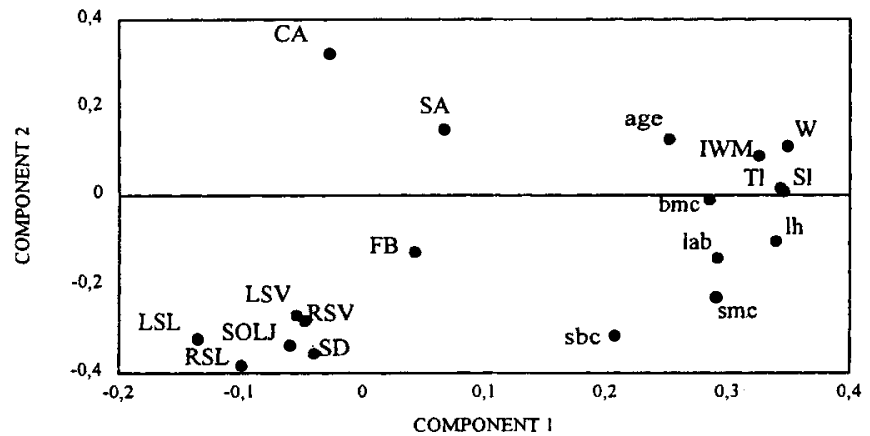

A

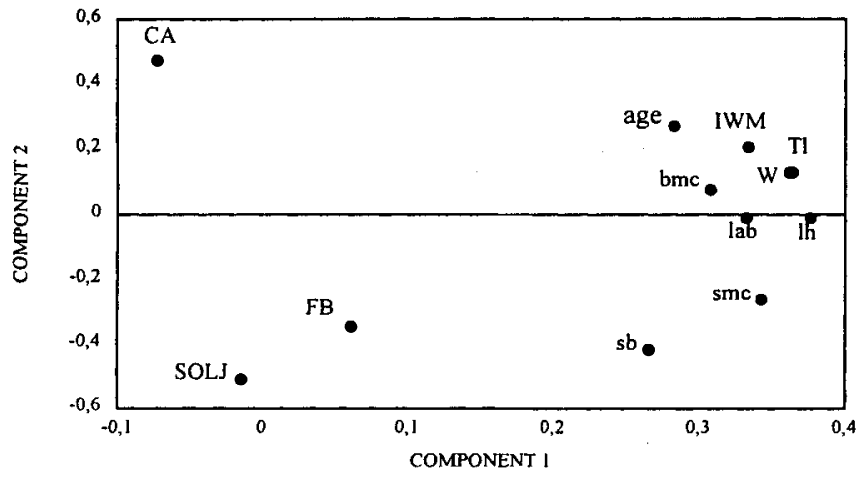

B

Fig. 2. A.- Plot weight of principal components of all variables. The first component is "LENGTHS" and second is "INDEX AND SCUTES". B.Plot weight of principal components of variables without scutes series. The first component is "LENGTHS" and second is "INDEX".

For identificatioin of other Abbreviations see caption of Figure 1. 2.Factor $l$

In order to clarify the second group, a new PCA without the scute series was performed, to exclude its effect on the variance. In this case, $78.5 \%$ of the variance was explained by the two components, showing two independent groups where, on the one hand, the new CA and SOLJ are closer and FB is more isolated, and on the other, the rest of the variables are grouped together with Tl. (Fig 2B) (Table 2).

A model to explain the relationship between $\mathrm{Tl}$ (dependent variable) and the indices (independent variables) was described using a stepwise multiple regression analysis giving the following polynomial: $\mathrm{Tl}=33.32-0.26 \mathrm{CA}+10.49 \mathrm{FB}+74.45 \mathrm{SOLJ}(\mathrm{F}=$ 1.96; $\mathrm{Df}=3$ ) showing that the fit was not significant. Thus, the indices are independent of $\mathrm{Tl}$.

Also, if the indices are compared against each other, they prove to be independent of each other (Table 3). Once the relationship between the variables and $\mathrm{Tl}$ is described with PCA, linear models are calculated using the $\mathrm{Tl}$ as an independent variable and the rest as dependent (Table 4).

Table 1.

Factor loadings (pattern) extracted by Principal Components Analysis (PCA) using all variables

\begin{tabular}{ccc}
\hline Variable & $\begin{array}{c}\text { LENGTH } \\
\text { (Component 1) }\end{array}$ & INDEX \& SCUTES (Component 2) \\
\hline Age & 0.2524 & 0.1253 \\
AS & 0.0676 & 0.1484 \\
b-mc & 0.2854 & -0.0121 \\
CA & -0.0266 & 0.3211 \\
DS & -0.0392 & -0.3578 \\
FB & 0.0436 & -0.1291 \\
IWM & 0.3255 & 0.0874 \\
lab & 0.2919 & -0.1424 \\
hl & 0.3395 & -0.1056 \\
LVS & -0.0534 & -0.2710 \\
LLS & -0.1340 & -0.3242 \\
RLS & -0.0982 & -0.3846 \\
RVS & -0.0465 & -0.2839 \\
s-b & 0.2083 & -0.3170 \\
Sl & 0.3462 & 0.0065 \\
s-mc & 0.2908 & -0.2291 \\
SOLJ & -0.0586 & -0.3389 \\
Tl & 0.3490 & 0.1096 \\
W & 0.3434 & 0.0143 \\
\hline
\end{tabular}

$\mathrm{Tl}$, Total length; Sl, standard length; $\mathrm{W}$, weight; s-b, distance from snout to the base of the barbels; lab, width of the snout at the height of the barbels; b-mc, distance from the base of the barbels to the cartilaginous arch of mouth; s-mc, distance from the tip of snout to the cartilaginous arch of mouth; hl, length of the head. Scute series: anal, AS; dorsal, DS left, LLS; lateral right, RLS; ventral left, LVS; ventral right, RVS; IWM, internal width of mouth; $\mathrm{CA}=\mathrm{b}-\mathrm{mc}-\mathrm{s}-\mathrm{b} ; \mathrm{FB}=\mathrm{s}-\mathrm{mc}$ : lab; $\mathrm{SOLJ}=\mathrm{s}-\mathrm{mc}$ : IWM

Table 2.

Factor loadings (pattern) extracted by Principal Components Analysis (PCA) using variables without scute series

\begin{tabular}{ccc}
\hline Variable & $\begin{array}{c}\text { LENGTHS } \\
\text { (Component 1) }\end{array}$ & $\begin{array}{c}\text { INDICES } \\
\text { (Component 2) }\end{array}$ \\
\hline Age & 0.2831 & 0.2677 \\
b-mc & 0.3081 & 0.0747 \\
CA & -0.0719 & 0.4726 \\
FB & 0.0612 & -0.3462 \\
IWM & 0.3338 & 0.2044 \\
lab & 0.3323 & -0.0122 \\
hl & 0.3766 & -0.0129 \\
s-b & 0.2662 & -0.4174 \\
s-mc & 0.3427 & -0.2632 \\
SOLJ & -0.0134 & -0.5118 \\
Tl & 0.3644 & 0.1263 \\
W & 0.3620 & 0.1264 \\
\hline
\end{tabular}

TI, Total length; SI, standard length; $\mathrm{W}$, weight; s-b, distance from snout to the base of the barbels; lab, width of the snout at the height of the barbels; b-mc, distance from the base of the barbels to the cartilaginous arch of mouth; s-mc, distance from the tip of snout to the cartilaginous arch of mouth; hl, length of the head; IWM, internal width of mouth; CA $=b-m c-s-b ; F B=s-m c: l a b ; S O L J=s-m c: I W M$

To compare Tl to the weight, both variables were log transformed (base 10). The main relationships between the analysed morphometric variables, plus their dependence and relationship with $\mathrm{Tl}$, and the independence of the three calculated indices, was 
demonstrated analysing all the data and considering the data by ages. Length in each year class ( $\mathrm{Tl} 2+$ and $\mathrm{Tl} 3+$ ) was compared to the index at its respective ages $(2+)$ or $(3+)$. Table 5 shows that FB is the most stable index, with values between 1.25 and 1.81 , whereas CA varied between -1.7 and 0.9 and SOLJ between 1.63 and 2.35 .

Table 3.-

Simple linear regression analysis between indices where a: Intercept; $b$ : slope; $r$ : correlation coefficient and $p$ : level of significance

\begin{tabular}{lcccc}
\hline & $\mathrm{a}$ & $\mathrm{b}$ & $\mathrm{r}$ & $\mathrm{p}$ \\
\hline $\begin{array}{l}\text { Dependent variable CA } \\
\text { Independent variables }\end{array}$ & & & & \\
FB & 21.03 & -18.16 & -0.402 & 0.0001 \\
SOLJ & -34.82 & 55.7 & 0.492 & 0.0001 \\
& & & & \\
$\begin{array}{l}\text { Dependent variable FB } \\
\text { Independent variable SOLJ }\end{array}$ & 1.97 & -0.87 & -0.346 & 0.0067 \\
\hline
\end{tabular}

$\mathrm{CA}=\mathrm{b}-\mathrm{mc}-\mathrm{s}-\mathrm{b} ; \mathrm{FB}=\mathrm{s}-\mathrm{mc}: \mathrm{lab} ; \mathrm{SOLJ}=\mathrm{s}-\mathrm{mc}: \mathrm{IWM} ; \mathrm{b}-\mathrm{mc}$, distance from the base of the barbels to the cartilaginous arch of mouth; s-mc, distance from the tip of snout to the cartilaginous arch of mouth; s-b, distance from snout to the base of the barbels; lab, width of the snout at the height of the barbels; IWM, internal width of mouth

Table 4.-

Simple linear regression analysis between $\mathrm{Tl}$ and the remaining variables, where a: Intercept; $b$ : slope; $r$ : correlation coefficient and $p$ : level of significance

\begin{tabular}{rcccc}
\hline Independent variable TI & $\mathrm{a}$ & $\mathrm{b}$ & $\mathrm{r}$ & $\mathrm{p}$ \\
\hline Dependent variable & & & & \\
log W & 6.245 & 3.169 & 0.922 & 0 \\
age & -0.907 & 0.038 & 0.754 & 0 \\
$\mathrm{~b}-\mathrm{mc}$ & 10.833 & 0.227 & 0.696 & 0 \\
lab & 17.476 & 0.393 & 0.743 & 0 \\
$\mathrm{hl}$ & 36.513 & 1.423 & 0.869 & 0 \\
IWM & 8.444 & 0.353 & 0.844 & 0 \\
$\mathrm{SI}$ & -2.807 & 0.829 & 0.987 & 0 \\
s-b & 18.02 & 0.263 & 0.459 & 0,0002 \\
s-mc & 30.42 & 0.52 & 0.683 & 0 \\
\hline
\end{tabular}

$\mathrm{Tl}$, Total length; $\mathrm{Sl}$, standard length; $\mathrm{W}$, weight; s-b, distance from snout to the base of the barbels; lab, width of the snout at the height of the barbels; b-mc, distance from the base of the barbels to the cartilaginous arch of mouth; s-mc, distance from the tip of snout to the cartilaginous arch of mouth; hl, length of the head; IWM, internal width of mouth
Table 5-

Simple linear regression analysis between $\mathrm{Tl}(2+$ and $3+)$ as independent variable and the CA, FB and SOLJ indices (dependent variables), where a: Intercept; $b$ : slope; $r$ : correlation coefficient and $p$ : level of significance

\begin{tabular}{cccccc}
\hline $\begin{array}{c}\text { Independent } \\
\text { variable }\end{array}$ & $\begin{array}{c}\text { Dependent } \\
\text { variable. }\end{array}$ & $\mathrm{a}$ & $\mathrm{b}$ & $\mathrm{r}$ & $\mathrm{p}$ \\
\hline \multirow{2}{*}{$\mathrm{Tl}(2+)$} & $\mathrm{CA}$ & 13.98 & -0.25 & -0.29 & 0.119 \\
& FB & 1.05 & 0.005 & 0.27 & 0.1492 \\
& SOLJ & 0.607 & -0.0007 & -0.174 & 0.359 \\
& & & & & \\
& & & & & \\
$\mathrm{Tl}(3+)$ & CA & 5.88 & -0.11 & -0.146 & 0.439 \\
& FB & 1.38 & 0.001 & 0.081 & 0.669 \\
& SOLJ & 0.6 & -0.0007 & -0.101 & 0.594 \\
\hline
\end{tabular}

$\mathrm{Tl}$, Total length; $\mathrm{CA}=\mathrm{b}-\mathrm{mc}-\mathrm{s}-\mathrm{b} ; \mathrm{FB}=\mathrm{s}-\mathrm{mc}:$ lab; SOLJ = s-mc $: I W M$, where $b-m c=$ distance from the base of the barbels to the cartilaginous arch of mouth; s-b = distance from snout to the base of the barbels; s-mc $=$ distance from the tip of snout to the cartilaginous arch of mouth; lab = width of the snout at the height of the barbels; IWM = internal width of mouth

\section{References}

Garrido-Ramos, M.A.; Soriguer, M.C.; de la Herranz, R.; Jamilena, M.; Ruiz Rejon, C.; Domezain, A.; Hernando, J.A.; Ruiz Rejon, M., 1997: Morphometric and genetic analysis as proof for the existence of two sturgeon species in the Guadalquivir River. Marine Biology 129: 33 - 39

Hernando J.A.; Arlati, G.; Domezain, A.; Soriguer, M.C.; Poliakova, L.A.; Domezain, J.; Vallespin, C.; Bravo, R., 1999: Morphometric study of Acipenser naccarii Bonaparte, 1836, in fish farm individuals. $J$. Appl. Ichthyol. This issue.

Holcik, J.; Banarescu, P.; Evans., D.E., 1989: A general introduction to fishes. In: The freshwater fishes of Europe Vol 1/II.. Ed. J. Holcik, J. Aula-Verlag, Wiesbaden. pp. 18 - 147.

Soljan, T., 1975: I pesci dell'Adriatico. Mondadori. Verona. 522 pp 